\title{
Bifurcation of Axons from Cranial Sensory Neurons Is Disabled in the Absence of Npr2-Induced cGMP Signaling
}

\author{
Gohar Ter-Avetisyan, Fritz G. Rathjen, and Hannes Schmidt \\ Max Delbrück Center for Molecular Medicine, 13092 Berlin, Germany
}

\begin{abstract}
Axonal branching is a prerequisite for the establishment of complex neuronal circuits and their capacity for parallel information processing. Previously, we have identified a cGMP signaling pathway composed of the ligand C-type natriuretic peptide (CNP), its receptor, the guanylyl cyclase natriuretic peptide receptor 2 (Npr2), and the cGMP-dependent kinase I $\alpha$ (cGKI $\alpha$ ) that regulates axon bifurcation of dorsal root ganglion (DRG) neurons in the spinal cord. Now we asked whether this cascade also controls axon bifurcation elsewhere in the nervous system. An Npr2-lacZ reporter mouse line was generated to clarify the pattern of the CNP receptor expression. It was found that during the period of axonal outgrowth, Npr2 and cGKI $\alpha$ were strongly labeled in neurons of all cranial sensory ganglia (gV, gVII, gVIII, $\mathrm{gIX}$, and $\mathrm{gX}$ ). In addition, strong complementary expression of CNP was detected in the hindbrain at the entry zones of sensory afferents. To analyze axon branching in individual Npr2-positive neurons, we generated a mouse mutant expressing a tamoxifen-inducible variant of Cre recombinase expressed under control of the Npr2-promoter (Npr2-CreER ${ }^{\mathrm{T} 2}$ ). After crossing this strain with conditional reporter mouse lines, we revealed that the complete absence of Npr2 activity indeed prohibited the bifurcation of cranial sensory axons in their entrance region. Consequently, axons only turned in either an ascending or descending direction, while collateral formation and growth of the peripheral arm was not affected. These findings indicate that in neurons of the cranial sensory ganglia, as in DRG neurons, cGMP signals are necessary for the execution of an axonal bifurcation program.
\end{abstract}

Key words: axonal branching; cGKI; cGMP signaling; CNP; cranial sensory ganglia; Npr2

\section{Introduction}

Axonal branching enables an individual neuron to connect with distinct targets, thereby providing a framework for the parallel processing of neural signals in the CNS. Impairments of programs that trigger axonal branching might result in functional alterations (Schmidt and Rathjen, 2010; Gallo, 2011; Gibson and Ma, 2011; Lewis et al., 2013).

Dorsal root ganglion (DRG) neurons projecting into the spinal cord already proved to be an attractive system for the molecular analysis of axon branching. Intracellular labeling of DRG neurons has shown that after entering the spinal cord, sensory afferents exhibit axonal branching of first, second, and higher order (Brown, 1981). At the first axonal branch point in the cord,

\footnotetext{
Received Sept. 30, 2013; revised Nov. 18, 2013; accepted Nov. 23, 2013.

Author contributions: G.T.-A., F.G.R., and H.S. designed research; G.T.-A. and H.S. performed research; G.T.-A. and H.S. analyzed data; G.T.-A., F.G.R., and H.S. wrote the paper.

This work was supported by Deutsche Forschungsgemeinschaft Grants SFB665 and F0R2060. We are grateful to Drs. Rosemarie Grantyn (Charité, Berlin, Germany) and Alistair Garratt (Max Delbrück Center for Molecular Medicine) for critical reading of the manuscript. We thank Dr. Hagen Wende, Andrea Leschke (both Max Delbrück Center for Molecular Medicine), and the transgenic core facility of the Max Delbrück (enter for Molecular Medicine for their help during the generation of the Npr2-lacZ and the Npr2-CreER ${ }^{\mathrm{T} 2}$ mutant mice; Dr. Sylvia Arber (Friedrich Miescher Institute, Basel, Switzerland) for providing the tau-mGFP strain; Madlen Driesner and Karola Bach for technical support; and Dr. Kira Balueva (Max Delbrück Center for Molecular Medicine) for the help with tamoxifen application. The authors declare no competing financial interests.

Correspondence should be addressed to either of the following: Fritz G. Rathjen, Max Delbrück Center for Molecular Medicine, Robert Rössle Str. 10, 13092 Berlin, Germany. E-mail: rathjen@mdc-berlin.de; or Hannes Schmidt, Max Delbrück Center for Molecular Medicine, Robert Rössle Str. 10, 13092 Berlin, Germany. E-mail: hannes.schmidt@mdc-berlin.de.

DOI:10.1523/JNEUROSCI.4183-13.2014

Copyright $\odot 2014$ the authors $\quad 0270-6474 / 14 / 340737-11 \$ 15.00 / 0$
}

DRG axons bifurcate in the dorsal column into two stem axons, which proceed further in the rostrocaudal plane. From the stem, axons bud numerous ventrally directed collaterals that in turn form higher-order branches (Ozaki and Snider, 1997; Schmidt and Rathjen, 2010).

The molecular mechanisms controlling the bifurcation of the main axon and collateral formation at the second-order branch point appear to be fundamentally different (Schmidt and Rathjen, 2010; Gallo, 2011). A cGMP signaling cascade composed of C-type natriuretic peptide (CNP), the receptor guanylyl cyclase Npr2 (also known as GC-B or Npr-B), and the cGMPdependent kinase I $\alpha$ (cGKI $\alpha$, also termed PKGI $\alpha$ ) regulates the first-order bifurcation of DRG axons in the dorsal column. In the absence of any of these components, sensory axons no longer bifurcate and instead form solitary stem axons that turn in either the rostral or caudal direction (Schmidt et al., 2002, 2007, 2009; Zhao and Ma, 2009; Zhao et al., 2009). Factors implicated in collateral formation of DRG axons are currently unknown, while terminal branching is regulated by SAD (synapses of amphids defective) kinases (Lilley et al., 2013).

A major open question was to what extent the mechanism underlying the bifurcation of DRG afferents in the spinal cord can be generalized. To obtain a reliable answer, it was necessary to provide information on the molecular basis of axon bifurcation in the hindbrain. Specifically, we aimed to investigate whether CNP-induced cGMP signaling also controls bifurcation of sensory afferents from the cranial ganglia, which develop from a different source than spinal ganglia (Lleras-Forero and Streit, 
2012). For the analysis of the Npr2 expression profile, we generated an Npr2-lacZ reporter mouse line. To clarify the impact of Npr2-induced cGMP signaling, we applied a genetic strategy for sparse labeling of Npr2-expressing neurons that involved the generation of a mouse mutant encoding a tamoxifen-inducible Cre recombinase under control of the Npr2 promoter (Npr2CreER $^{\mathrm{T} 2}$; Feil et al., 1996; Rotolo et al., 2008).

By crossing this Npr2-CreER ${ }^{\mathrm{T} 2}$ driver strain with reporter mouse lines, we revealed that the bifurcation of axons from neurons of all cranial sensory ganglia is impaired in the absence of Npr2. Thus, axons of cranial sensory neurons, which are similar to DRG neurons, use Npr2-induced cGMP signaling to trigger axon bifurcation in the hindbrain. We demonstrate that a cGMPdependent signaling pathway controls first-order axon bifurcation but not higher-order branching of sensory neurons entering the CNS at any level.

\section{Materials and Methods}

Mice. Animals were handled in accordance with protocols approved by the local animal use and care authority (LaGeSo, Berlin). The Npr2-lacZ mouse line was generated by standard procedures replacing exon 1 of the Npr2 gene by a lacZ expression cassette with a nuclear localization sequence followed by a polyA stretch and a self-excising Cre recombinase cassette flanked by two loxP sites. The latter contains a testis-specific promoter as well as a neomycin resistance gene. A $10.4 \mathrm{~kb}$ fragment containing exons $1-3$ of the Npr2 gene was isolated and cloned by gap repair from BAC (bacterial artificial chromosome) clone bMQ331a20 (Source BioScience) for the generation of the targeting construct (Lee et al., 2001). Embryonic day (E) 14.1 ES cells (129/Ola) were electroporated and clones that had incorporated the targeting vector into their genome were selected by G418 and analyzed for homologous recombination after digestion with PstI by Southern blot analysis using a $5^{\prime}$ probe amplified by primers $5^{\prime}$-TCATTTAATTTTGCTGACTG-3' and $5^{\prime}$-TTACTTGTTTAGAAACAGG-3' and a $3^{\prime}$ probe amplified by primers $5^{\prime}$-GTAA GCCAAGAAAGTGGGG-3' and $5^{\prime}$-GCAGACAGAGAGAAGGCATAG$3^{\prime}$. Blastocysts were injected and chimeras that transmitted the mutant Npr2-lacZ gene were identified by mating Npr2 $2^{\text {lacZ/+ }}$ males to C57BL/6J females. Similarly, using the same BAC clone, the Npr2-CreER ${ }^{T 2}$ strain was generated by replacing exon 1 of the Npr2 gene by coding sequences of the tamoxifen-inducible Cre recombinase (CreER ${ }^{\mathrm{T} 2}$; Feil et al., 1997) followed by a polyA stretch and a neomycin resistance gene flanked by FRT [FLP (flippase) recombinase target] sites. AB2.1 ES cells (129S7/ SvEvBrd) were electroporated and screened by Southern blotting using the same probes as for the Npr2-lacZ mutant mouse. Subsequently, the neomycin segment was removed by crossbreeding with the FLP-deleter strain

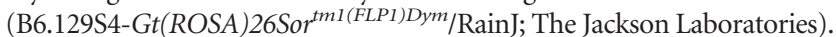

Other mouse lines used in this study were as follows: Z/AP (The Jackson Laboratory; Lobe et al., 1999), tau-mGFP (Hippenmeyer et al., 2005), Npr2-cn (The Jackson Laboratory; Tsuji and Kunieda, 2005), cGKI (Wegener et al., 2002), CNP-lacZ (Schmidt et al., 2009). Cross breeding of Npr2-CreER ${ }^{\mathrm{T} 2}$ mice with reporter lines has been previously described in detail (Schmidt et al., 2013).

Genotyping of Npr2-lacZ and Npr2-CreER ${ }^{T 2}$. Routine genotyping was performed by PCR amplification of genomic DNA isolated by the High Pure PCR Template Preparation Kit according to manufacturer's instructions (Roche). For the Npr2-lacZ strain, a 398 bp fragment of the $L a c Z$ allele and a $348 \mathrm{bp}$ fragment of the wild-type allele were amplified using oligonucleotides P1 (5'-TGCCACCCTATCCTTAGTCC-3'), P2 (5'-GTGTTCTGGCAGCACCAC- $\left.3^{\prime}\right)$, and P3 (5'-TCGCTATTACG CCAGCTG-3'). PCR analysis of the Npr2-CreER ${ }^{T 2}$ strain using oligonucleotides P4 (5'-CTCAGATTCCTCCCTTCTCG-3'), P5 (5' -GGCATAGCT CAGGTTGTGTT- $3^{\prime}$ ), and P6 (5' -TTGGACATGGTGGAATTCAT- $3^{\prime}$ ) resulted in the amplification of a $356 \mathrm{bp}$ fragment of the mutant allele and a 456 bp fragment of the wild-type allele.

Tamoxifen administration. To induce alkaline phosphatase (AP) expression in embryos containing the Z/AP reporter, tamoxifen was administered $(0.1 \mathrm{mg} / \mathrm{g}$ body weight $)$ by oral gavage to timed pregnant animals at E9.5 as described previously (Joyner and Zervas, 2006). Embryos were collected at E12.5, E13.5, or E15.5 to analyze reporter expression in central projections and collaterals of Npr2-positive cranial sensory neurons. For recombination of the tau-mGFP reporter gene, 4-hydroxytamoxifen (Sigma-Aldrich) was prepared according to a previously described protocol (Indra et al., 1999) and administered $(2 \mu \mathrm{g} / \mathrm{g}$ body weight) to timed pregnant mice at E9.5. GFP expression was analyzed in E12.5 embryos by immunostaining of $50 \mu \mathrm{m}$ cryosections.

Histology. For whole-mount 5-bromo-4-chloro-3-indolyl- $\beta$-D-galactopyranoside (X-gal) staining, embryos were fixed in PBS containing $0.2 \%$ glutaraldehyde, $50 \mathrm{~mm}$ EGTA, $\mathrm{pH} 7.3$, and $20 \mathrm{~mm} \mathrm{MgCl}_{2}$ at $4^{\circ} \mathrm{C}$ for $15-30$ min, depending on the developmental stage. Tissues were then equilibrated in $\beta$-galactosidase ( $\beta$-gal) wash solution $\left(20 \mathrm{mM} \mathrm{MgCl}_{2}, 0.02 \%\right.$ Nonidet$\mathrm{P} 40,0.01 \%$ sodium deoxycholate in PBS) and subsequently stained in $\beta$-gal wash solution containing $0.5 \mathrm{mg} / \mathrm{ml} \mathrm{X}$-gal and $5 \mathrm{~mm}$ potassium ferrocyanide and ferricyanide at room temperature or $37^{\circ} \mathrm{C}$. After development of a blue color, the reaction was stopped by transferring the embryos to PBS containing $2 \mathrm{mM} \mathrm{MgCl}_{2}$. After two rounds of washing in PBS, the probes were postfixed in $4 \%$ paraformaldehyde and further processed for clearing before microscopic analysis.

For X-gal staining or immunohistochemical detection of $\beta$-gal in tissue sections, embryos were fixed in Zamboni's fixative (Stefanini et al., 1967) at room temperature for 30-90 min according to the developmental stage of the specimen. Following fixation, tissues were cryoprotected, embedded in OCT compound (Sakura Finetek), and sectioned at a thickness of $25 \mu \mathrm{m}$ for X-gal staining or $15 \mu \mathrm{m}$ for immunohistochemistry.

$\mathrm{X}$-gal staining of frozen sections was done as described above for whole-mount embryos.

Detection of AP activity in parasagittal vibratome sections of $\mathrm{Npr}^{\mathrm{CreERT2/+}}{ }^{\mathrm{C}} \mathrm{Z} / \mathrm{AP}{ }^{+}$or Npr2 ${ }^{\mathrm{CreERT2} / \mathrm{cn}} ; \mathrm{Z} / \mathrm{AP} \mathrm{P}^{+}$mouse embryos was performed as previously described (Schmidt et al., 2013).

Optical clearing. X-gal-stained whole-mount embryo preparations were cleared in a solution containing $4 \mathrm{~m}$ urea, $10 \%(\mathrm{v} / \mathrm{v})$ glycerol, and $0.1 \%(\mathrm{v} / \mathrm{v})$ Triton X-100 for 3 weeks followed by incubation in a solution containing $8 \mathrm{~m}$ urea and $0.1 \%$ glycerol for $4 \mathrm{~d}$ at $4^{\circ} \mathrm{C}$ (Hama et al., 2011). The whole-mount embryos were further incubated in the first solution for 1-2 months, depending on embryonic age.

Vibratome sections processed for AP staining were dehydrated using a graded ethanol series $[25,50,75,100 \%(\mathrm{v} / \mathrm{v})]$. After dehydration, the sections were cleared in benzyl alcohol/benzyl benzoate (BABB; one part/ two parts). After imaging, the sections were rehydrated and stored in PBS at $4^{\circ} \mathrm{C}$.

Immunohistochemistry, generation of antibodies, DiI labeling, and apoptosis detection. Immunofluorescent staining and DiI labeling were performed as described previously (Schmidt et al., 2007; Schmidt and Rathjen, 2011). The following primary antibodies were used in combination with appropriate fluorophore-conjugated secondary antibodies: chicken anti- $\beta$-galactosidase (1:5000; Jackson ImmunoResearch), rabbit anti- $\beta$-gal (1:20,000; Cappel), rabbit anti-GFP (1:10,000; Jackson ImmunoResearch), mouse anti-neurofilament-M $(7.5 \mu \mathrm{g} / \mathrm{ml} ; 2 \mathrm{H} 3$, Developmental Hybridoma Bank), rabbit anti-Cre (1:10,000; Millipore), and rabbit anti-L1 (Rathjen and Schachner, 1984). Guinea pig anti-cGKI $\alpha$ $(1: 25,000)$ or guinea pig anti-Npr2 $(1: 10,000)$ have been generated to the $\mathrm{N}$-terminal region of mouse cGKI $\alpha$ (amino acid residues 2-89) or to the extracellular region of mouse Npr2, respectively, by injections of the antigens at fortnightly intervals (Charles River).

Apoptosis was detected using TumorTACS In Situ Apoptosis Detection Kit (Trevigen) followed by standard eosin staining protocol. From each genotype, seven sagittal sections were analyzed for apoptosis and quantified.

Image acquisition and analysis. Images of whole-mount X-galprocessed embryos and of $250 \mu \mathrm{m}$ vibratome sections stained for AP activity were obtained using a microscope (Axiovert 135) equipped with a charge-coupled device camera (AxioCam HRc) and acquisition software (AxioVision3.1; all from Carl Zeiss). Vibratome sections were imaged in BABB clearing solution in a $50 \mathrm{~mm}$ Lumox hydrophilic culture dish. Confocal images of immunohistochemical stainings and DiIlabeling experiments were captured with a Carl Zeiss LSM 710 NLO laser scanning microscope using ZEN 2010 software. The obtained data were 
A
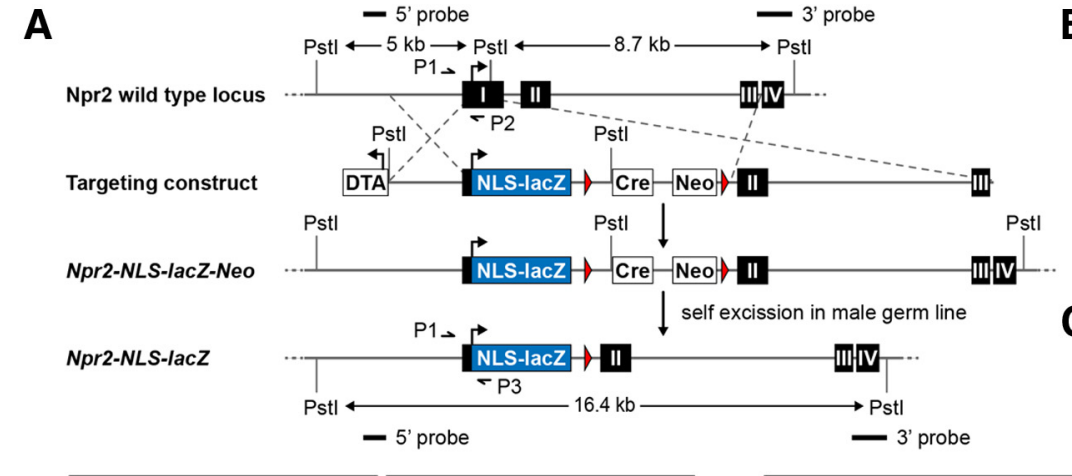

B

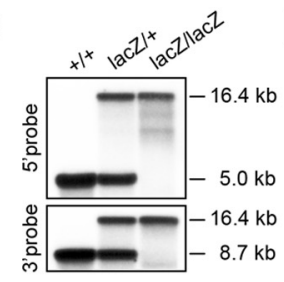

C

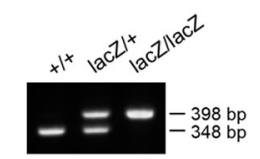

D DRG membrane fraction $+/+$ lacZ/+ lacZ/lacZ

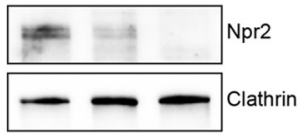
DRG lysate $+/+$ lacZ/+ lacZ/lacZ

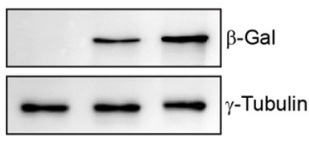

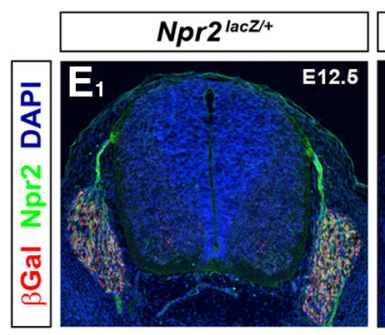
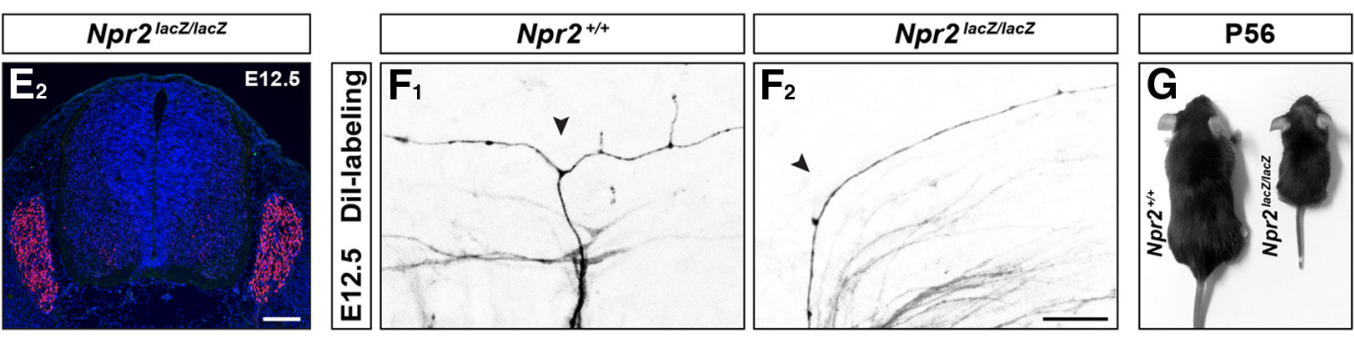

Figure 1. An Npr2-lacZ mouse strain as reporter of the Npr2 expression profile. $\boldsymbol{A}$, Targeting strategy for the generation of the Npr2-lacZ mouse line. $\boldsymbol{B}-\boldsymbol{D}$, Southern blot (B), PCR genotyping (C), and Western blot analyses (D) of wild-type, Npr2 ${ }^{\text {lacZ/+ }}$, and Npr2 ${ }^{\text {lacz/lacZ }}$ mice. $\boldsymbol{E}_{1}, \boldsymbol{E}_{2^{\prime}}$ Immunohistochemical analysis of transverse sections of Npr2 $2^{\text {lacZ/+ }}\left(\boldsymbol{E}_{1}\right)$ and Npr2 $2^{\text {lacZ/lacZ }}\left(\boldsymbol{E}_{2}\right)$ spinal cords at E12.5 using antibodies against $\beta$-gal and Npr2 confirms the absence of Npr2 expression in DRG neurons from Npr2 ${ }^{\text {laczllacZ }}$ mice. Nuclei were visualized by DAPI stain. $F$, Dorsal views of Dil-labeled axons from DRG neurons from control and Npr2 ${ }^{\text {lacz/lacZ }}$ embryos at E12.5 show a loss of axon bifurcation in Npr2-deficient animals. Fluorescence images are inverted. Lateral, bottom; caudal, left. G,

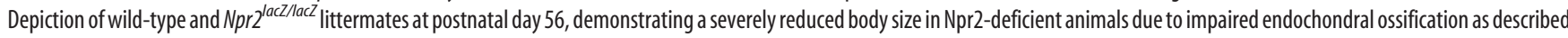
previously for other Npr2 mutants (Tamura et al., 2004; Tsuji and Kunieda, 2005; Geister et al., 2013). Scale bars: $\boldsymbol{E}, 100 \mu \mathrm{m} ; \boldsymbol{F}, 25 \mu \mathrm{m}$.

imported to the Adobe Photoshop CS4 software, cropped, and assembled in Adobe Illustrator CS3. The brightness and contrast were adjusted uniformly across entire images maintaining signal linearity and confirming that fluorescence intensity was not saturated.

Quantification and statistical analysis. For the colocalization study of Npr2, cGKI $\alpha$, and neurofilament-M in cranial sensory ganglia, 15 horizontal cryosections from three mouse embryos were analyzed for each ganglion. Quantification of the triple immunostainings with DAPI counterstaining was done on the images of sections obtained by confocal laser scanning microscopy using a $40 \times$ oil-immersion objective. The total number of the cells and the number of colocalized cells were counted in a $4000 \mu \mathrm{m}^{2}$ field with an appropriate imaging channel and with simultaneous detection of 2-fluorescence or 3-fluorescence channels, respectively.

The size of the trigeminal funiculus was quantified in confocal images of transverse cryostat sections of littermate wild-type and $N p r^{\text {lacZllac }}$ embryos labeled with an antiserum specific for cGKI $\alpha$ ( $\geq 60$ sections from three embryos from each genotype were measured) using the ImageJ $1.47 \mathrm{q}$ software (National Institutes of Health).

Apoptotic cells were quantified on seven serial sagittal sections of the trigeminal ganglion for each genotype by counting the number of dead cells (stained black) in an area of $25,000 \mu \mathrm{m}^{2}$.

The bifurcation behavior of individual cranial sensory axons was analyzed by counting AP-stained or GFP-labeled axons using light microscopy or confocal laser scanning microscopy, respectively.

\section{Results}

Coexpression of Npr 2 and cGKI $\alpha$ in all cranial sensory ganglia and complementary localization of CNP in axonal entry zones of the hindbrain

To identify candidate neuronal populations that might use Npr2mediated cGMP signaling to trigger axon bifurcation, we generated a targeted Npr2-lacZ reporter mouse to study the expression profile of Npr2 in the developing nervous system (Fig. 1A). Southern blot and PCR analysis indicated the correct integration of the target vector into the mouse genome (Fig. $1 B, C$ ). Western blotting and immunostainings show the absence of Npr2 protein in Npr2-lacZ homozygotes and the presence of $\beta$-gal in extracts or cryostat sections of embryonic DRGs (Fig. 1D-E). Npr2 $2^{\text {lacZ/lac } Z}$ mice lack the bifurcation of DRG axons at the dorsal root entry zone and develop a dwarfed phenotype as reported for the spontaneous $\mathrm{cn} / \mathrm{cn}$ mutant mouse, which expresses an inactive form of Npr2 due to a missense mutation (Fig. $1 F-G$; Tsuji and Kunieda, 2005; Schmidt et al., 2007). Together, these data indicated the correctness of the targeting strategy.

To correlate the expression of Npr2 with the localization of CNP and cGKI $\alpha$ in embryonic whole mounts or cryostat sections, we used X-gal or immunostaining of Npr2-lacZ heterozygous mice. At E10.5, Npr2 becomes strongly expressed in all cranial sensory ganglia ( $\mathrm{gV}$, gVII, gVIII, gIX, and gX) and in DRGs (Fig. $2 A_{1}-L_{1}$ ), which is consistent with in situ hybridization experiments in data bases (http://www.eurexpress.org/). In addition, Npr2 was also detected at E10.5-E12.5 in the nasal region, in the mesencephalon, and at the midbrain-hindbrain border. Importantly, an overlapping expression pattern with $\mathrm{Npr} 2$ in all cranial sensory ganglia was detected for cGKI $\alpha$ and neurofilament-M (Fig. $2 M_{1}-Q_{2}$; note that due to a nuclear localization signal, $\beta$-gal representing Npr2 is detected in the nuclei of cells while antibody staining for cGKI $\alpha$ or neurofilament-M reveals a cytosolic distribution). About 75\% of DAPIpositive cells coexpress Npr2, cGKI $\alpha$, and neurofilament in the different cranial sensory ganglia (Fig. $2 R$ ). The remaining population of $\sim 25 \%$ of Npr2-negative, cGKI $\alpha$-negative, and neurofilament-negative cells might be precursor or supporting cells. Except for small populations in ventral layers or in rhombomere 1, Npr2 is not found in cells of the spinal cord or hindbrain, respectively, at the stages examined (Fig. $2 D_{1}-F_{1}, H_{1}-L_{1}$ ).

Furthermore, a strong complementary distribution of CNP, the ligand of Npr2, was observed at these stages in the hindbrain of a CNP-lacZ reporter mouse. CNP expression starts at E9.5 in the alar plate of rhombomeres 2, 4, and 6/7, where trigeminal, facial, vestibulocochlear, glossopharyngeal, and vagal sensory ax- 

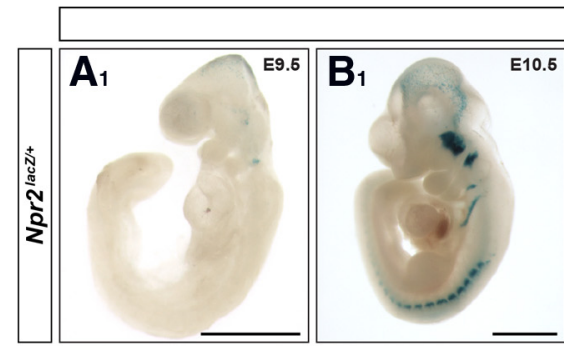

$$
\text { X-Gal }
$$
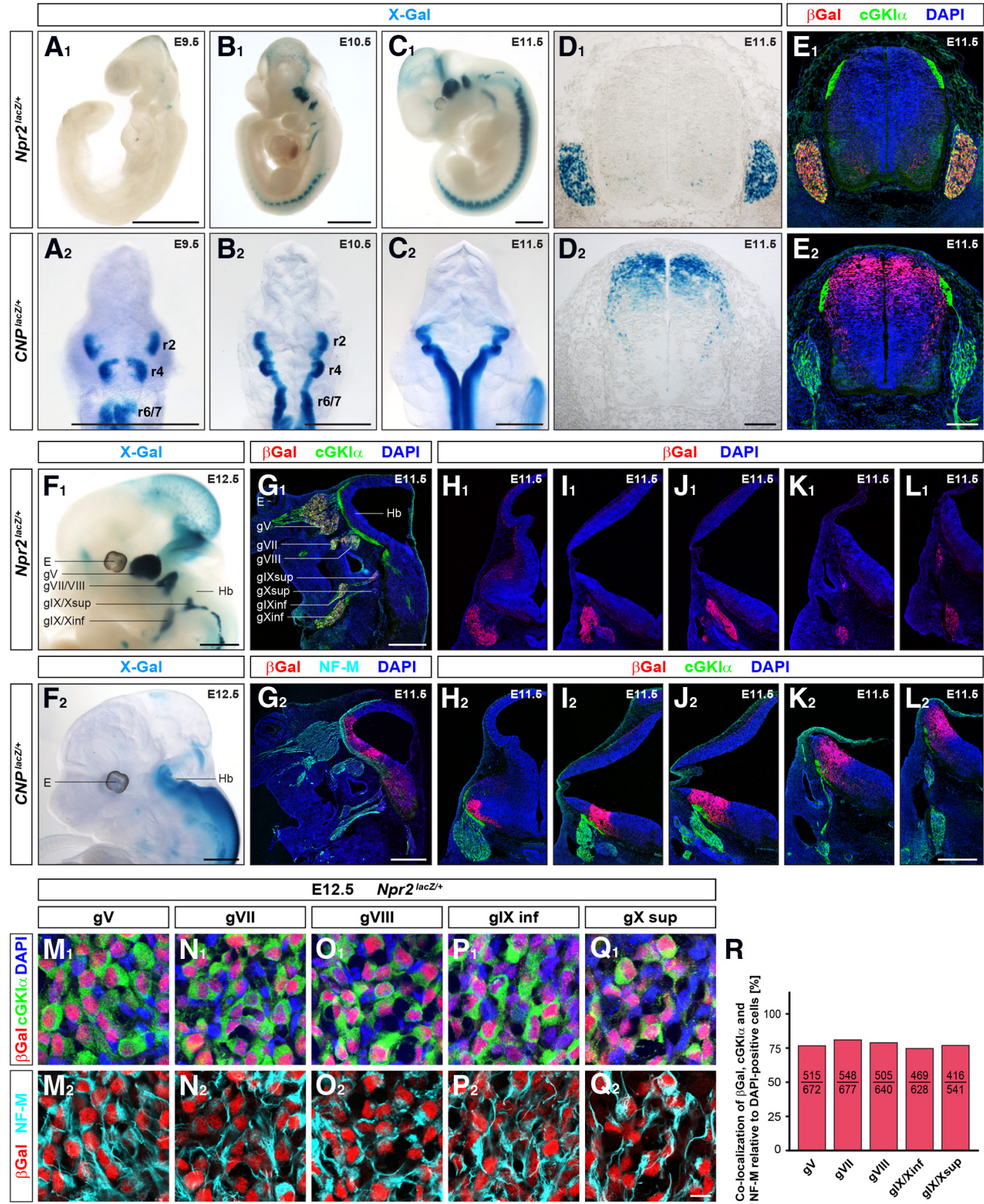

Figure 2. Complementary distribution of CNP in the hindbrain, and coexpression of Npr2 and CGKl $\alpha$ in cranial sensory neurons. $A_{1}-D_{1}, \beta$-gal activity in Npr2 ${ }^{\text {lacz/+ }}$ whole-mount embryos $\left(\boldsymbol{A}_{\boldsymbol{1}}-\boldsymbol{C}_{1}\right)$ and in a transverse spinal cord section $\left(\boldsymbol{D}_{1}\right)$ reveals sites of Npr2 expression at the indicated developmental stages. $\boldsymbol{A}_{2}-\boldsymbol{D}_{2}$, Embryonic expression pattern of CNP. X-gal staining represents the localization of CNP at the indicated developmental stages in dorsal views of the head region of $C N P^{\text {lacz/+ }}$ whole-mount embryos $\left(\boldsymbol{A}_{2}-\boldsymbol{C}_{2}\right)$ and in a transverse spinal cord section $\left(\boldsymbol{D}_{2}\right) . \boldsymbol{E}_{1}, \boldsymbol{E}_{2}$, Immunohistochemical detection of $\beta$-gal and $c G K l \alpha$ in transverse sections of the spinal cord in Npr2 ${ }^{\text {lacz/+ }}$ or $\mathrm{CNP}^{\text {lacz/+ }}$ mice, respectively, documenting coexpression of Npr2 and CGKI $\alpha$ in DRG neurons and CNP in dorsal regions of the spinal cord. $\boldsymbol{F}_{1}, \boldsymbol{F}_{2}, \mathrm{X}$-gal stainings of Npr ${ }^{\text {lacz/++ }}$ whole-mount embryo preparations at E12.5 $\left(\boldsymbol{F}_{1}\right.$; lateral view) show a strong expression of Npr2 in all cranial sensory ganglia, while $\beta$-gal activity representing CNP expression in CNPlacz/+ mice $\left(\boldsymbol{F}_{2}\right)$ is complementarily localized in the hindbrain. $\mathbf{G}-\mathbf{L}$, This is confirmed by immunohistochemical detection of $\beta$-gal in parasagittal sections of the hindbrain region $\left(\boldsymbol{G}_{1}, \boldsymbol{G}_{2}\right)$ and in matching pairs of serial transverse sections from E11.5 Npr2 $2^{\text {lacz/+ }}$ and CNP ${ }^{\text {lacz/+ }}$ embryos at the level of $\mathrm{gV}\left(\boldsymbol{H}_{1}, \boldsymbol{H}_{2}\right), \mathrm{gVII}\left(\boldsymbol{I}_{1}, \boldsymbol{I}_{2}\right), \mathrm{gVIIII}\left(\boldsymbol{J}_{1}, \boldsymbol{J}_{2}\right), \mathrm{gIX}\left(\boldsymbol{K}_{1}, \boldsymbol{K}_{2}\right)$, and $\mathrm{gX}\left(\boldsymbol{L}_{1}, \boldsymbol{L}_{2}\right)$. Coimmunostaining reveals an overlapping distribution of $\beta$-gal with $\mathrm{CGKI} \alpha$ expression in the cranial sensory ganglia of the Npr2 ${ }^{\text {lacZ/+ }}$ reporter $\left(\boldsymbol{G}_{1}\right)$, which corresponds to the area stained by an antibody against neurofilament-M in $C N P^{p a c Z /+}$ mice $\left(\boldsymbol{G}_{\mathbf{2}}\right) \cdot \boldsymbol{H}_{\mathbf{2}}-\boldsymbol{L}_{\mathbf{2}}$, Sites of CNP expression in the hindbrain are directly opposed to the entry zones of ingrowing cranial sensory axons as detected by colabeling for $\mathrm{CGKI} \alpha$. $\boldsymbol{M}-\mathbf{Q}$, The

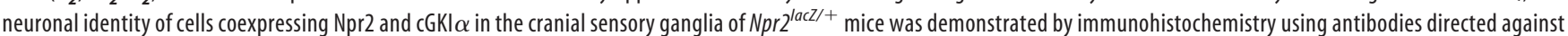

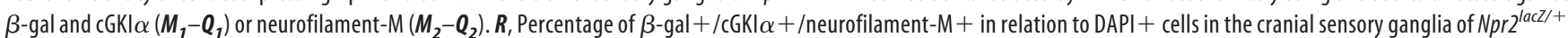
embryos at E12.5. Absolute numbers counted are indicated in the columns. Nuclei in $\boldsymbol{E}$ and $\mathbf{G}-\boldsymbol{Q}$ were visualized by DAPI. E, Eye; $g$, ganglion; $\mathrm{Hb}$, hindbrain; r, rhombomere. Scale bars: $A-C, 1 \mathrm{~mm} ; \mathbf{D}-\mathbf{E}, 100 \mu \mathrm{m} ; \boldsymbol{F}-\mathbf{L}, 500 \mu \mathrm{m} ; \mathbf{M}-\mathbf{Q}, 10 \mu \mathrm{m}$. 


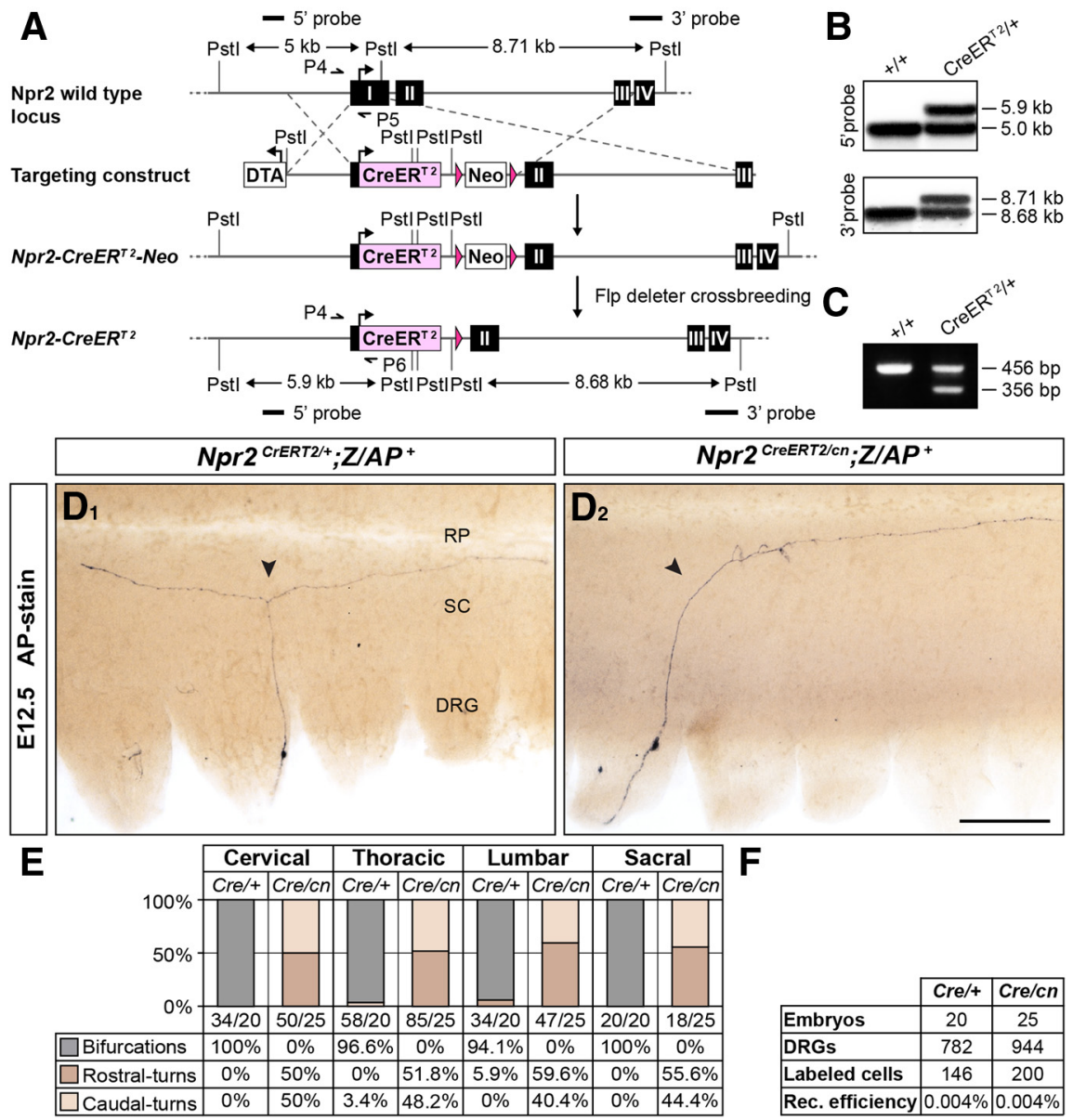

Figure 3. The Npr2-CreER ${ }^{T 2}$ mouse line crossed to a reporter line enables the visualization of individual Npr2-expressing neurons. $\boldsymbol{A}_{\text {, }}$ Targeting strategy for the generation of the Npr2-CreERT mouse line. $B$, $C$, Southern blot $(\boldsymbol{B})$ and PCR genotyping $(\boldsymbol{C})$ of wild-type and $\mathrm{Npr}^{\text {(reeRT2/+}}{ }^{\text {mice. }} \boldsymbol{D}$, Representative examples of alkaline phosphatase-stained DRG neurons in whole-mount spinal cord preparations

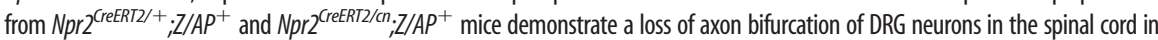
Npr2-deficient animals. E, Quantification of the bifurcation behavior of DRG neurons from Npr2 heterozygous (Cre/ + ) and homozygous deficient (Cre/cn) embryos. Total numbers of counted axons and numbers of analyzed embryos are indicated below the columns. $\boldsymbol{F}$, Efficiency of the tamoxifen-induced recombination of the AP reporter constructin DRG neurons from $\mathrm{Nprr}^{\text {(reERT2/+ }} ; \mathrm{Z} / \mathrm{AP} \mathrm{P}^{+}$and Npr2 $2^{\text {CreeRT2/ }}$ cn;Z/AP ${ }^{+}$mice. RP, Roof plate; SC, spinal cord. Scale bar: $D, 250 \mu \mathrm{m}$

ons enter the hindbrain (Fig. $2 A_{2}-C_{2}, F_{2}-L_{2}$ ). As development proceeds, the structures between rhombomeres 2,4 , and $6 / 7$ and more caudal parts of the hindbrain as well as the dorsal spinal cord also become strongly positive for $\mathrm{CNP}$ (Fig. $2 \mathrm{C}_{2}-E_{2}$ ). At these early developmental stages, $\mathrm{CNP}$ is not found in the cranial sensory ganglia or DRGs (Fig. $2 A_{2}-E_{2}$ ).

Together, the expression of Npr2 and cGKI $\alpha$ in all neurons of the cranial sensory ganglia and the complementary localization of CNP in the hindbrain suggest a function of Npr2-induced cGMP signaling for ingrowing cranial sensory axons.

\section{Analysis of axonal arborization of Npr2-expressing neurons by sparse transgenic labeling}

The investigation of the impact of Npr2-mediated cGMP signaling on axonal branching of cranial sensory neurons requires the visualization of individual axons. While axon tracing by DiI is a versatile and fast method for the analysis of axonal branching in DRG neurons, its application to the small cranial sensory ganglia, such as the jugular or nodose ganglia at early developmental stages, would be challenging. We therefore applied a genetic strategy for sparse labeling of Npr2-expressing neurons involving the generation of a mutant encoding a tamoxifen-inducible vari- ant of Cre recombinase under control of the Npr2 promoter (Npr2-CreER ${ }^{\mathrm{T} 2}$; Fig. 3A; Feil et al., 1996). Southern blot and PCR analysis confirmed correct integration of the target vector (Fig. $3 B, C$ ). To validate the genetic strategy for the analysis of axon bifurcation, we compared the branching patterns of DRG neurons within the embryonic spinal cord of Npr2 heterozygous mice, which resemble the wild-type phenotype (Schmidt et al., 2007), with those of homozygous Npr2deficient animals. Tamoxifen-dependent activation of Cre recombinase in mouse embryos resulting from crossbreeding of heterozygous Npr2-CreER ${ }^{\mathrm{T} 2}$ mice with mice double-transgenic for the spontaneous lossof-function mutation Npr2-cn and a conditional reporter allele (Z/AP or tau-mGFP; Lobe et al., 1999; Hippenmeyer et al., 2005) released reporter gene expression in the genetically defined subset of Npr2-expressing cells (Fig. 3D; Schmidt et al., 2013). In line with previous findings (Schmidt et al., 2007), we observed that $97.3 \%$ of the $146 \mathrm{AP}$-positive DRG neurons of Npr2 heterozygous embryos showed a bifurcation of their central axons, whereas in the absence of $\mathrm{Npr} 2$ activity all DRG axons (200 AP-positive neurons) revealed only turns and no bifurcation (Fig. 3E). Only axons that could be traced back to a cell soma in DRG were counted. No reporter activity was detected in the absence of tamoxifen. Assuming an average of 5000 neurons per DRG, a recombination frequency of $0.004 \%$ was calculated for the Z/AP system (Fig. 3F), which is in good approximation with earlier reports (Badea et al., 2009).

Axons of cranial sensory neurons fail to bifurcate in Npr2-deficient mice

After validation of the Npr2-CreER ${ }^{\mathrm{T} 2}$ mouse model as a useful tool to visualize axonal branching of Npr2-positive neurons, we studied the central projections of cranial sensory axons using the reporter lines Z/AP or tau-mGFP. Figure 4 shows examples of cranial sensory axons ( 79 of 82 axons visualized) that bifurcate in an ascending and a descending arm when Npr2 is present. In contrast, in the absence of Npr2 activity, all 163 visualized axons from the different cranial sensory ganglia turned without bifurcation in a descending or ascending stem axon (Fig. $4 A-D, G, H$ ). In addition to the bifurcation error, we occasionally observed aberrant cranial sensory axon projections at the entry zone, as illustrated for an axon from gIX (Fig. $4 F$ ). This axon turned in ascending direction but then looped backward and grew into the opposite direction. Similar observations have been occasionally made for DRG axons in the absence of Npr2 (Schmidt et al., 2007).

Bifurcation of sensory axons at the entry zone of the brainstem results in the formation of two axon branches that ascend and descend in the ventrolateral region of the hindbrain. A lack of bifurcation at the entry zone, as observed in Npr2 mutants, should thus evoke a significant reduction of axon numbers in the lateral hindbrain (see Fig. 8, scheme). As a 

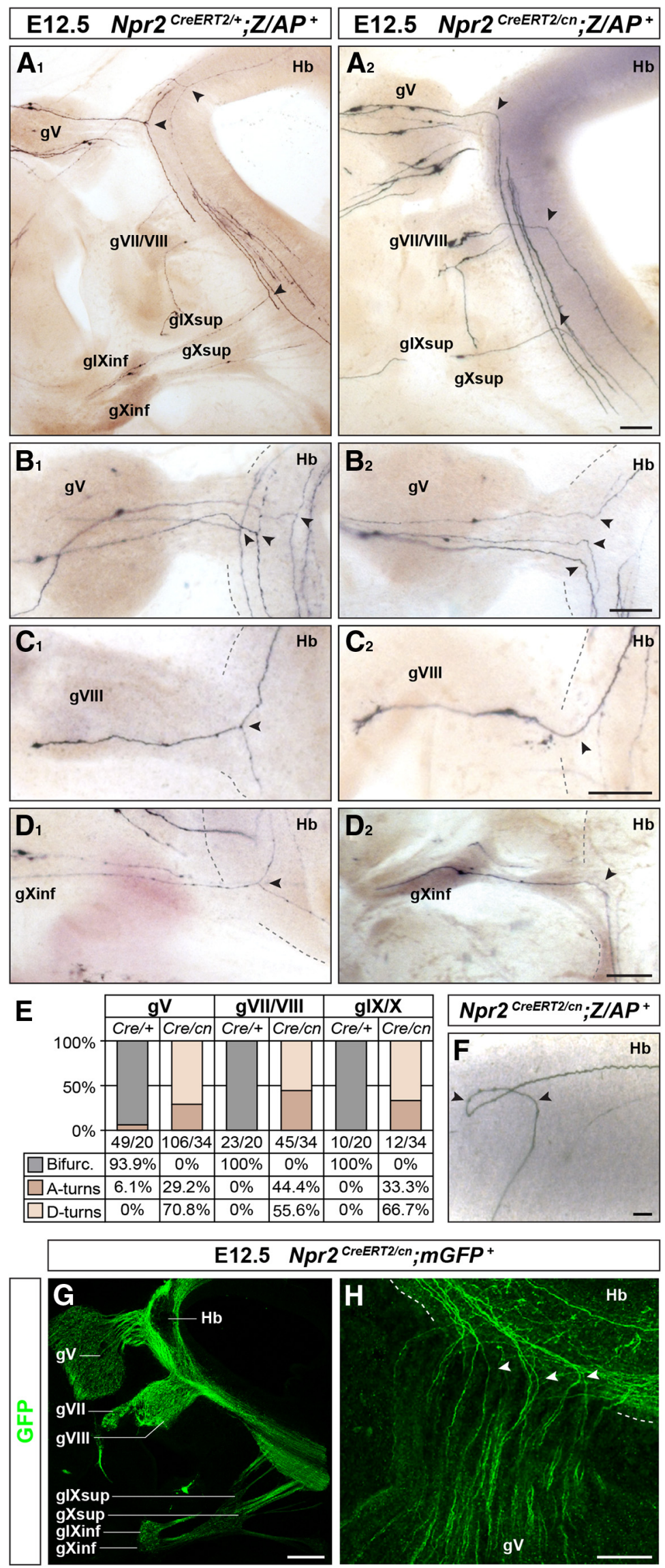

$2^{\text {CreERT2/cn }} ; m G F P^{+}$

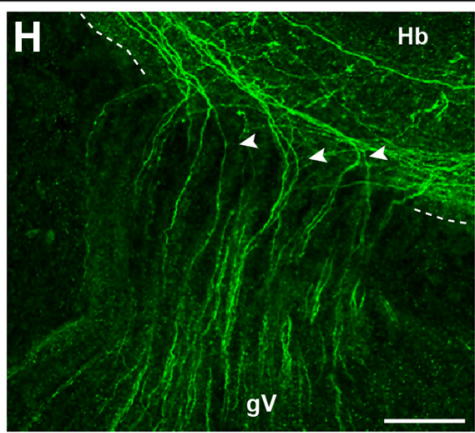

Figure 4. Bifurcation of axons from cranial sensory neurons depends on Npr2.A-D, AP staining of matched pairs of parasagittal sections from tamoxifen-treated $\mathrm{Npr}^{\text {(reERT2/+ }} ; \mathrm{Z} / \mathrm{AP}{ }^{+}$and $\mathrm{Npr} 2^{\text {(reeRT2//n }} ; \mathrm{Z} / \mathrm{AP}{ }^{+}$mice demonstrates a loss of axon bifurcation in measure of axon number, the area of anti-cGKI $\alpha$ immunoreactivity was quantified in cross sections of the hindbrain at the level of the trigeminal nerve. The cGKI $\alpha$-labeled area in the trigeminal entry zone of E12.5 embryos amounted to $50 \%$ of wild-type controls in the absence of Npr2 activity (Fig. $5 A, B)$. This method only gives an indirect estimate of axon number; however, the measurements strongly suggest that, in mice lacking bifurcation in the entry zone of rhombomere 2 , such zones contain substantially fewer sensory axon arms within the trigeminal entry region of the hindbrain, and this lack of sensory axon arms is not caused by an increase in the number of apoptotic cells (Fig. 5C,D).

To study whether CNP and cGKI $\alpha$, the two other known components of the cGMP cascade that controls axon bifurcation of DRG neurons, also influence the bifurcation of cranial sensory neurons, we performed DiI tracing for trigeminal axons in CNP and cGKI mutant mice. This analysis demonstrated bifurcation errors at the hindbrain for CNP and cGKI knock-outs, indicating that these two components together with Npr2 act in a signaling cascade that regulates branching of cranial sensory neurons (Fig. 6A, $B$ ).

\section{Collateral formation of axons from} cranial sensory ganglia is not impaired in the absence of Npr2

After bifurcation, the two arms of the stem axons further branch out by generating collaterals at the axon shafts. Analysis of the Z/AP reporter mouse at more advanced embryonic stages revealed that

$\longleftarrow$

the central projection of cranial sensory neurons. $\boldsymbol{E}$, Quantification of the bifurcation behavior of cranial sensory neurons from Npr2 heterozygous ( $\mathrm{Cre} /+$ ) and homozygous deficient ( $\mathrm{Cre} / \mathrm{cn}$ ) embryos. Total numbers of counted axons and numbers of analyzed embryos are indicated. $\boldsymbol{F}$, AP-labeling of a parasagittal section from an E12.5 Npr2 ${ }^{\text {CreERT2/ }} ; \mathrm{C}_{\mathrm{Z}} / \mathrm{AP}^{+} \mathrm{em}-$ bryo whose mother received tamoxifen at $\mathrm{E} 9.5$ shows an example of occasionally observed directionally aberrant turning behavior. Without bifurcating, a central axon from gIX first turned in an ascending direction and then looped backwards in the hindbrain. $\mathbf{G}-\boldsymbol{H}$, Anti-GFP immunostaining of cryosections of E12.5 Npr2 ${ }^{\mathrm{CreERT2} / \mathrm{cn}} ; \mathrm{mGFP}^{+}$embryos whose mothers received 4-hydroxytamoxifen at $E 9.5$ indicates Cre-induced recombination in Npr2-expressing cells. In parasagittal sections of the hindbrain area, GFP-immunoreactivity is detected in all cranial sensory ganglia and their axonal projections (G). Higher magnification reveals trigeminal axons that fail to bifurcate in the hindbrain $(\boldsymbol{H})$. The broken line indicates the border of the hindbrain and arrowheads show nonbifurcating trigeminal axons. g, Ganglion; Hb, hindbrain. Scale bars: $\boldsymbol{A}$, $200 \mu \mathrm{m} ; \boldsymbol{B}-\boldsymbol{D}, 100 \mu \mathrm{m} ; \boldsymbol{F}, 50 \mu \mathrm{m} ; \boldsymbol{G}, 250 \mu \mathrm{m} ; \boldsymbol{H}, 100 \mu \mathrm{m}$. 

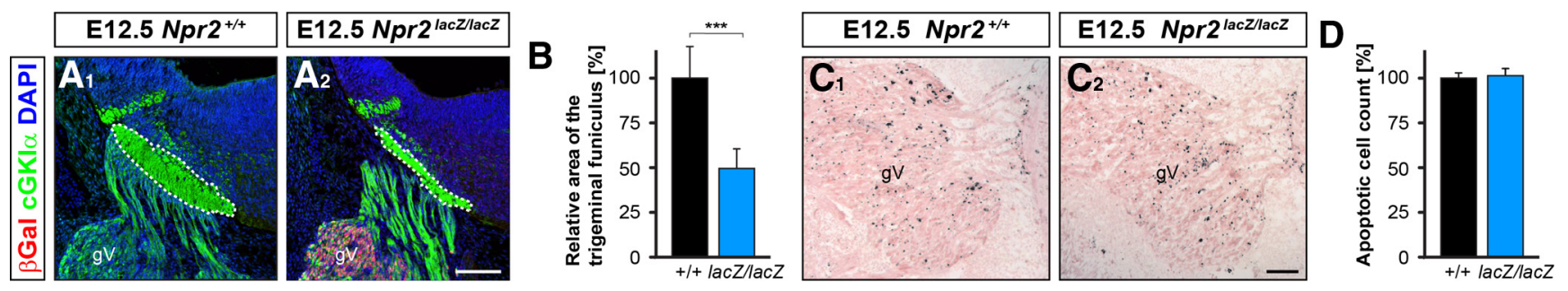

Figure 5. A, cGKl $\alpha$ immunostaining reveals a reduction in the size of the trigeminal funiculus (outlined by broken lines) in Npr2 ${ }^{\text {lacz/lacz }}$ mice. $B$, Quantification of the relative cGKI $\alpha$-positive area of the developing trigeminal funiculus in transverse sections of wild-type and Npr2 knock-out embryos (at least $n=60$ sections were analyzed from 3 embry0s of each genotype). $p<0.001$, Mann-Whitney U test. Error bars represent SD. C, D, TUNEL-detection $(\boldsymbol{C})$ and quantification $(\boldsymbol{D})$ of apoptotic cells in trigeminal ganglia at E12.5 in control and Npr2 ${ }^{\text {lacZ/lacZ }}$ mice. Error bars represent SE. Scale bars: $\boldsymbol{A}, \boldsymbol{C}, 100 \mu \mathrm{m}$.

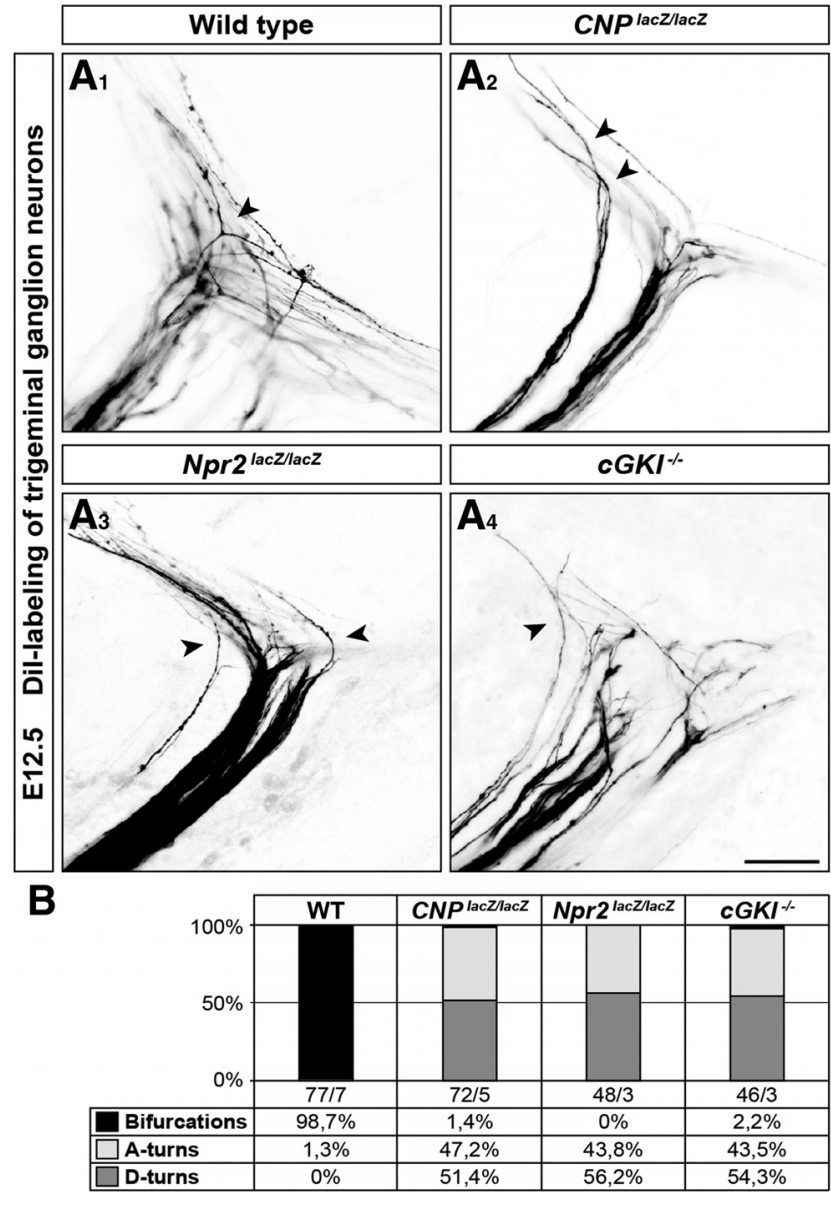

Figure 6. CNP-induced cGMP signaling triggers the bifurcation of central axons from trigeminal ganglion neurons in the hindbrain. $A$, Dil tracing of axon projections in parasagittal sections from wild-type $\left(\boldsymbol{A}_{1}\right), C N P^{\text {lacZ/lacZ }}\left(\boldsymbol{A}_{2}\right), N p r 2^{\text {lacZ/lacZ }}\left(\boldsymbol{A}_{3}\right)$, and $C G K I^{-/-}\left(\boldsymbol{A}_{4}\right)$ mice at E12.5. Axons from mice deficient for any of the components of the CNP-induced cGMP signaling pathway fail to bifurcate at the hindbrain. $B$, Quantification of Dil analysis showing the percentage of bifurcating, only ascending, or only descending trigeminal axons in the indicated genotypes. The numbers of single axons counted and analyzed embryos are given for each genotype. Scale bar, $50 \mu \mathrm{m}$.

the formation of collaterals by cranial sensory axons was not impaired in the absence of Npr2 activity (Fig. $7 A, B$ ). It is important to note that the inactivation of cGMP signaling via Npr2 did not destroy the overall organization of the hindbrain or the formation of L1-positive axon tracts (Fig. $7 C-G$ ). In addition, no gross alterations in the peripheral processes of the ophthalmic branch of the trigeminal nerve in the absence of Npr2 were observed in whole mounts of the head region as detected by anti-L1 staining (Fig. $7 H$ ), which is consistent with our observations on DRG axons (Schmidt et al., 2007).

In summary, axonal bifurcation of neurons from cranial sensory ganglia and DRGs is mediated in an analogous manner by Npr2-induced cGMP signaling.

\section{Discussion}

During the course of target-directed navigation, axons form branches at specific points either through activities of their growth cone or in the axon shaft. Axonal branching is essential for the development of a functional nervous system. It allows an individual neuron to communicate with multiple neurons. Interstitial branching at the axon shaft appears to be the dominating branching mode in the brain and often occurs after growth of the primary axon, as has been observed for corticospinal or sensory axons (Nakamura and O'Leary, 1989; Ozaki and Snider, 1997). Although axonal branching during development is of crucial importance for the functionality of the mature nervous system, our molecular understanding of this process is still limited (Schmidt and Rathjen, 2010; Gallo, 2011; Gibson and Ma, 2011; Lewis et al., 2013). Defining signaling mechanisms that regulate axonal branching is therefore important for our understanding of how the complex pattern of neuronal connections is shaped. In the past, we analyzed the branching of DRG axons entering the spinal cord, whereby we and others identified a cGMP-dependent signaling cascade essential for axonal bifurcation in vivo (Schmidt et al., 2002, 2007, 2009; Zhao and Ma, 2009; Zhao et al., 2009). In this study, it was our aim to extend these observations to other neuronal populations through the use of genetic tools that allowed the analysis of axon branching in the hindbrain.

Our main conclusions of this study are as follows (Fig. 8): (1) at early developmental stages we observed a strong colocalization of Npr2 and cGKI $\alpha$ in cranial sensory neurons and, importantly, a complementary expression of the ligand CNP in rhombomeres 2,4 , and $6 / 7$ of the hindbrain; (2) all neurofilament-positive neurons of cranial sensory ganglia as well as DRGs were found to express both Npr2 and cGKI $\alpha$; (3) in the absence of Npr2induced cGMP signaling, bifurcation of axons from cranial sensory ganglia was completely disabled, and turns only in one direction were observed; (4) the formation of interstitial collaterals that extend into the corresponding brainstem nuclei to form terminal arbors on second-order neurons was not impaired, indicating that other signaling systems are important for this type of branch formation; and (5) the overall pathfinding of Npr2positive axons in the CNS as well as in the periphery was not affected in the absence of this type of cGMP signaling. These overall building principles of branching and of target innervation are similar to the pattern found in the spinal cord, where Npr2- 

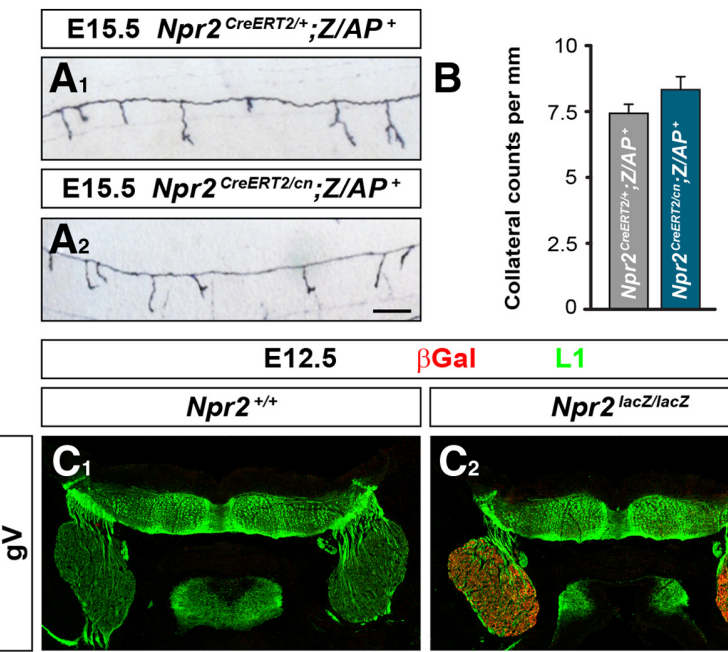

\begin{tabular}{cl}
$\beta$ Gal & L1 \\
\hline & Npr2 \\
\hline &
\end{tabular}
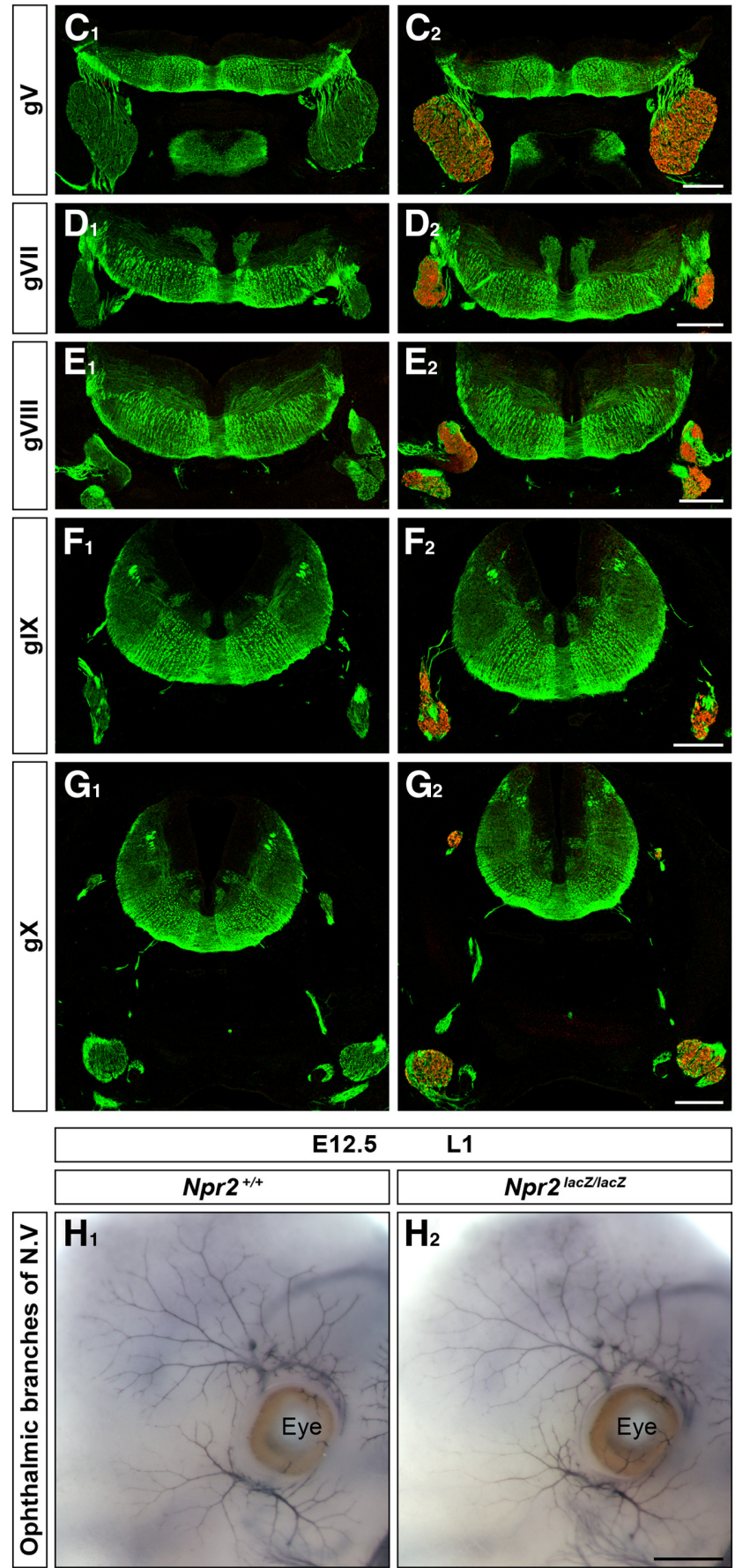

L1

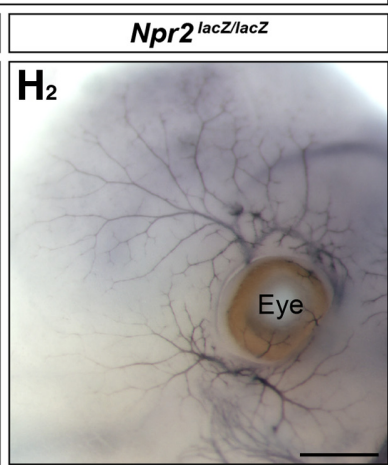

Figure 7. No alterations in collateral formation, in the overall pattern of embryonic hindbrain organization, or in trigeminal ophthalmic projections were observed in Npr2-deficient embryos. $\boldsymbol{A}$, In both $N p r 2^{\text {CreERT2/+ }} ; Z / A P^{+}$and $N p 2^{\text {CreERT2/Cn }} ; Z / A P^{+}$mice, collateral branches extend from the longitudinal axons of cranial sensory neurons in the hindbrain. $\boldsymbol{B}$, Analysis of induced cGMP signaling also mediates axonal bifurcation but not collateral formation or terminal branching.

Previously published tracing studies revealed that axons of several cranial ganglia bifurcate, thereby generating ascending and descending branches, which elongate along the lateral margin of the hindbrain. After a waiting period, interstitial collaterals are then generated from these stem axons that innervate their corresponding nuclear targets in the hindbrain, where they form terminal arbors on second-order neurons. For example, trigeminal collaterals terminate in the rostral principal nucleus and in the caudal spinal nucleus (Erzurumlu and Killackey, 1983; Erzurumlu and Jhaveri, 1992; Erzurumlu et al., 2010). Similarly, the axons of the bipolar neurons of the vestibular ganglion project to the ipsilateral hindbrain, where they bifurcate at the ventrolateral region of the lateral vestibular nucleus (Korte, 1979; Sato et al., 1989; McCue and Guinan, 1994; Imagawa et al., 1995, 1998; however, see also Maklad et al., 2010). Numerous collaterals are then elaborated. These terminate preferentially in the medial or superior vestibular nucleus (Sato et al., 1989; Maklad and Fritzsch, 2002, 2003). Axons of the bipolar type I and pseudo-unipolar type II spiral ganglion cells, which are part of the VIII ${ }^{\text {th }}$ cranial nerve, enter the brain, bifurcate, and form collaterals that innervate the subdivisions of the cochlear nucleus, the anteroventral cochlear nucleus, the posteroventral cochlear nucleus, and the dorsal cochlear nucleus (Fekete et al., 1984; Brown et al., 1988; Rubel and Fritzsch, 2002; Ryugo and Parks, 2003; Koundakjian et al., 2007; Appler and Goodrich, 2011). Axons of the nodose ganglion, which belong to the vagus nerve, enter the hindbrain, bifurcate, and extend rostrocaudally within the solitary tract before they arborize within the ipsilateral nucleus of the solitary tract and spinal trigeminal nucleus (Rinaman and Levitt, 1993).

The nerves of cranial sensory ganglia also contain motor axons that run through or are closely associated with these ganglia. Standard tracing techniques using DiI, HRP, or Golgi silver impregnation are therefore exposed to the risk that motor axons, in addition to sensory axons, become labeled. This obvious handicap of traditional axon tracing methods might explain why earlier studies reported that a relatively large proportion of trigeminal axons enter the hindbrain without bifurcation (Windle, 1926; Hayashi, 1980; Tsuru et al., 1989). Our approach for transgenic labeling of Npr2-positive neurons circumvented this problem and enabled a reliable visualization of cranial sensory axon paths. For this purpose, we generated a driver mouse strain encoding a tamoxifeninducible Cre recombinase under the promoter of Npr2, which was crossed with conditional reporter mice that contained floxed stop sequences upstream of the reporter allele. Expression of the reporter was only released after application of tamoxifen, which induced a transient activation and translocation of $\mathrm{CreER}^{\mathrm{T} 2}$ into the nuclei of Npr2-positive cells. We applied two reporters: Z/AP or tau-mGFP. Axons were detected by AP activity or by GFP fluorescence. The use of the

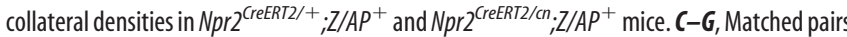
of transverse sections of E12.5 hindbrains from wild-type and Npr2 $2^{\text {lacz/lacZ }}$ mice were stained with an antibody against $L 1$ to reveal the gross anatomical organization of the hindbrain at the level of the different cranial sensory ganglia. As expected, $\beta$-gal was only detected in transgenic mice. $\boldsymbol{H}$, Whole-mount anti-L1 immunostaining indicates no major differences between $\mathrm{Npr}^{\text {lacZ/lacz }}$ animals and their wild-type littermate controls in the trigeminal ophthalmic projections surrounding the eye. Scale bars: $\boldsymbol{A}, 100 \mu \mathrm{m} ; \boldsymbol{C}-\boldsymbol{G}, 250 \mu \mathrm{m} ; \boldsymbol{H}, 500 \mu \mathrm{m}$. 


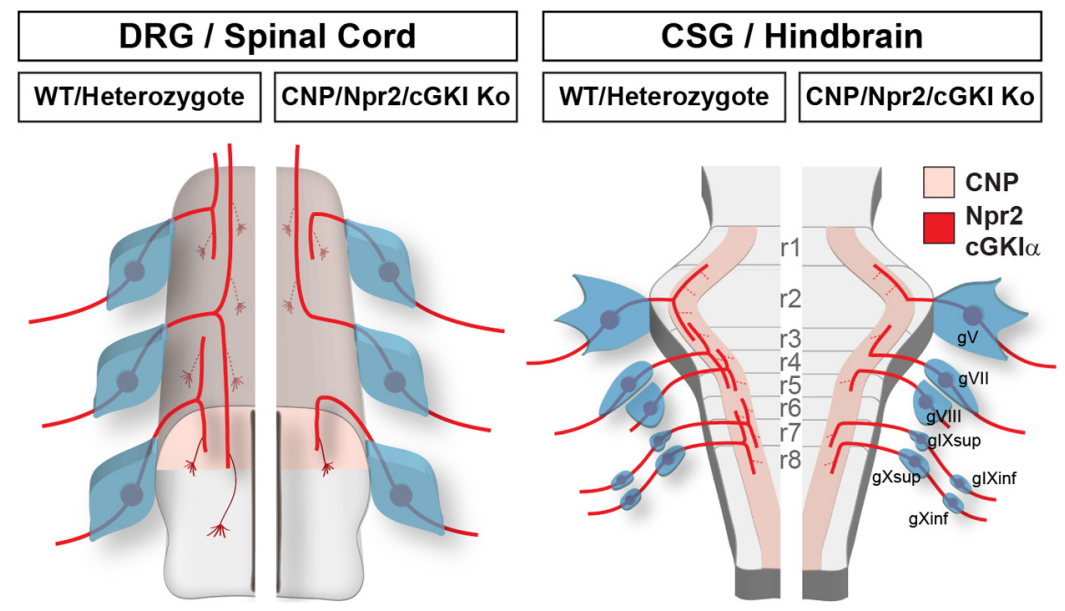

Figure 8. Schematic summary of the bifurcation defect observed in the absence of Npr2-induced cGMP-signaling in neurons of both DRG and cranial sensory ganglia. The localization of CNP, Npr2, and cGKl $\alpha$ are indicated. CSG, Cranial sensory ganglia; r1-r8, rhombomeres $1-8$.

$\mathrm{Z} / \mathrm{AP}$ reporter resulted in very low recombination frequencies, which facilitated the analysis of the paths of single axons in slice preparations. In contrast, the tau-mGFP reporter revealed a much higher frequency and the analysis of the trajectory of a single axon was only possible in stacks of confocal images. Both methods permitted a comprehensive and systematic analysis of axonal branching in the hindbrain at very early stages and demonstrated that all cranial Npr2 and neurofilament-positive sensory axons bifurcate in heterozygotes (corresponding to the wild-type situation). In the absence of Npr2-induced cGMP signaling, sensory axons only turn in one direction. DiI tracing experiments on the trigeminal ganglion in the absence of CNP, Npr2, or cGKI further support the notion that these three cGMP signaling components that were identified to be important for axonal branching in DRG neurons also control branching of cranial sensory neurons. In addition, a recently published study on DiI tracing of the VIII ${ }^{\text {th }}$ nerve in Npr2 $2^{c n / c n}$ mice also supports our overall conclusions ( $\mathrm{Lu}$ et al., 2011). In contrast, collateral formation is not impaired in the absence of Npr2-induced cGMP signaling, which is consistent with our view that distinct signaling cascades already exist in a single neuron to regulate distinct branching modes.

The cranial sensory ganglia contain neurons that transmit sensory information to the CNS. In contrast to the DRG neurons of the trunk, a substantial portion of the cranial sensory nervous system largely arises from specialized ectoderm-the sensory placodes - as well as from neural crest cells (D'AmicoMartel and Noden, 1983; Barlow, 2002; Lleras-Forero and Streit, 2012). This is exemplified by the trigeminal ganglion, which derives both from ectodermal placodes and neural crest cells migrating at the level of rhombomeres 1 and 2. The neurons of the inner ear, which transmit sound and the perception of rotational movements and accelerations to the brain, arise from the otic placode (Ladher et al., 2010). The petrosal placode contributes to the ninth cranial nerve (glossopharyngeal nerve), which innervates the tongue and the carotid sinus. The nodose placode contributes to the tenth cranial nerve (the vagus nerve), which detects sensory information from almost all of the organs in the body and is implicated in the regulation of cardiovascular, respiratory, gastrointestinal, and endocrine functions (Ratcliffe et al., 2011).
Behavioral studies aimed to understand why a T-shaped branching is of benefit for vertebrates to represent sensory information to the second-order neurons in the hindbrain or spinal cord are currently prevented by the postnatal lethality of global knock-outs for CNP, Npr2, or cGKI. In addition, the absence of CNP or Npr2, or mutations in CNP or Npr2, also impair long bone growth in mice and human patients, resulting in dwarf statures or overgrowth (Potter et al., 2009; Potter, 2011; Ter-Avetisyan et al., 2012). Further research requires additional mouse models that allow selective inactivation of the Npr2 signaling system in specific sensory ganglia.

Our study extends our initial observation of a cGMP signaling pathway that controls axonal bifurcation of DRG neurons to the population of cranial sensory neurons and therefore suggests a more common function of Npr2-induced cGMP signaling for axonal branching. Interestingly, at more advanced developmental stages, several other neuronal subpopulations in the brain are found to be positive for Npr2 and cGKI $\alpha$, including subpopulations in the cerebellum, hippocampus, and thalamus. However, the second messenger cGMP is implicated in several developmental and physiological processes in which cGMP signaling components are organized and function in different combinations (Lucas et al., 2000; Hofmann et al., 2006). A careful histological analysis of the localization of cGMP signaling components is therefore required before axonal branching studies are performed on these neuronal subpopulations. The genetic tools presented in this study provide helpful tools for the analysis of axonal branching of additional neuronal populations in the developing brain.

\section{References}

Appler JM, Goodrich LV (2011) Connecting the ear to the brain: Molecular mechanisms of auditory circuit assembly. Prog Neurobiol 93:488-508. CrossRef Medline

Badea TC, Hua ZL, Smallwood PM, Williams J, Rotolo T, Ye X, Nathans J (2009) New mouse lines for the analysis of neuronal morphology using CreER(T)/loxP-directed sparse labeling. PLoS One 4:e7859. CrossRef Medline

Barlow LA (2002) Cranial nerve development: placodal neurons ride the crest. Curr Biol 12:R171-R173. CrossRef Medline

Brown AG (1981) Organization in the spinal cord. Berlin: Springer.

Brown MC, Berglund AM, Kiang NY, Ryugo DK (1988) Central trajectories of type II spiral ganglion neurons. J Comp Neurol 278:581-590. CrossRef Medline

D'Amico-Martel A, Noden DM (1983) Contributions of placodal and neural crest cells to avian cranial peripheral ganglia. Am J Anat 166:445-468. CrossRef Medline

Erzurumlu RS, Jhaveri S (1992) Trigeminal ganglion cell processes are spatially ordered prior to the differentiation of the vibrissa pad. J Neurosci 12:3946-3955. Medline

Erzurumlu RS, Killackey HP (1983) Development of order in the rat trigeminal system. J Comp Neurol 213:365-380. CrossRef Medline

Erzurumlu RS, Murakami Y, Rijli FM (2010) Mapping the face in the somatosensory brainstem. Nat Rev Neurosci 11:252-263. CrossRef Medline

Feil R, Brocard J, Mascrez B, LeMeur M, Metzger D, Chambon P (1996) Ligand-activated site-specific recombination in mice. Proc Natl Acad Sci U S A 93:10887-10890. CrossRef Medline

Feil R, Wagner J, Metzger D, Chambon P (1997) Regulation of Cre recom- 
binase activity by mutated estrogen receptor ligand-binding domains. Biochem Biophys Res Commun 237:752-757. CrossRef Medline

Fekete DM, Rouiller EM, Liberman MC, Ryugo DK (1984) The central projections of intracellularly labeled auditory nerve fibers in cats. J Comp Neurol 229:432-450. CrossRef Medline

Gallo G (2011) The cytoskeletal and signaling mechanisms of axon collateral branching. Dev Neurobiol 71:201-220. CrossRef Medline

Geister KA, Brinkmeier ML, Hsieh M, Faust SM, Karolyi IJ, Perosky JE, Kozloff KM, Conti M, Camper SA (2013) A novel loss-of-function mutation in Npr2 clarifies primary role in female reproduction and reveals a potential therapy for acromesomelic dysplasia, Maroteaux type. Hum Mol Genet 22:345-357. CrossRef Medline

Gibson DA, Ma L (2011) Developmental regulation of axon branching in the vertebrate nervous system. Development 138:183-195. CrossRef Medline

Hama H, Kurokawa H, Kawano H, Ando R, Shimogori T, Noda H, Fukami K, Sakaue-Sawano A, Miyawaki A (2011) Scale: a chemical approach for fluorescence imaging and reconstruction of transparent mouse brain. Nat Neurosci 14:1481-1488. CrossRef Medline

Hayashi H (1980) Distributions of vibrissae afferent fiber collaterals in the trigeminal nuclei as revealed by intra-axonal injection of horseradish peroxidase. Brain Res 183:442-446. CrossRef Medline

Hippenmeyer S, Vrieseling E, Sigrist M, Portmann T, Laengle C, Ladle DR, Arber S (2005) A developmental switch in the response of DRG neurons to ETS transcription factor signaling. PLoS Biol 3:e159. CrossRef Medline

Hofmann F, Feil R, Kleppisch T, Schlossmann J (2006) Function of cGMPdependent protein kinases as revealed by gene deletion. Physiol Rev 86:123. CrossRef Medline

Imagawa M, Isu N, Sasaki M, Endo K, Ikegami H, Uchino Y (1995) Axonal projections of utricular afferents to the vestibular nuclei and the abducens nucleus in cats. Neurosci Lett 186:87-90. CrossRef Medline

Imagawa M, Graf W, Sato H, Suwa H, Isu N, Izumi R, Uchino Y (1998) Morphology of single afferents of the saccular macula in cats. Neurosci Lett 240:127-130. CrossRef Medline

Indra AK, Warot X, Brocard J, Bornert JM, Xiao JH, Chambon P, Metzger D (1999) Temporally controlled site-specific mutagenesis in the basal layer of the epidermis: comparison of the recombinase activity of the tamoxifen-inducible Cre-ER(T) and Cre-ER(T2) recombinases. Nucleic Acids Res 27:4324-4327. CrossRef Medline

Joyner AL, Zervas M (2006) Genetic inducible fate mapping in mouse: establishing genetic lineages and defining genetic neuroanatomy in the nervous system. Dev Dyn 235:2376-2385. CrossRef Medline

Korte GE (1979) The brainstem projection of the vestibular nerve in the cat. J Comp Neurol 184:279-292. CrossRef Medline

Koundakjian EJ, Appler JL, Goodrich LV (2007) Auditory neurons make stereotyped wiring decisions before maturation of their targets. J Neurosci 27:14078-14088. CrossRef Medline

Ladher RK, O’Neill P, Begbie J (2010) From shared lineage to distinct functions: the development of the inner ear and epibranchial placodes. Development 137:1777-1785. CrossRef Medline

Lee EC, Yu D, Martinez de Velasco L, Tessarollo L, Swing DA, Court DL, Jenkins NA, Copeland NG (2001) A highly efficient Escherichia colibased chromosome engineering system adapted for recombinogenic targeting and subcloning of BAC DNA. Genomics 73:56-65. CrossRef Medline

Lewis TL Jr, Courchet J, Polleux F (2013) Cell biology in neuroscience: cellular and molecular mechanisms underlying axon formation, growth, and branching. J Cell Biol 202:837-848. CrossRef Medline

Lilley BN, Pan YA, Sanes JR (2013) SAD kinases sculpt axonal arbors of sensory neurons through long- and short-term responses to neurotrophin signals. Neuron 79:39-53. CrossRef Medline

Lleras-Forero L, Streit A (2012) Development of the sensory nervous system in the vertebrate head: the importance of being on time. Curr Opin Genet Dev 22:315-322. CrossRef Medline

Lobe CG, Koop KE, Kreppner W, Lomeli H, Gertsenstein M, Nagy A (1999) $\mathrm{Z} / \mathrm{AP}$, a double reporter for cre-mediated recombination. Dev Biol 208: 281-292. CrossRef Medline

Lu CC, Appler JM, Houseman EA, Goodrich LV (2011) Developmental profiling of spiral ganglion neurons reveals insights into auditory circuit assembly. J Neurosci 31:10903-10918. CrossRef Medline

Lucas KA, Pitari GM, Kazerounian S, Ruiz-Stewart I, Park J, Schulz S, Chep- enik KP, Waldman SA (2000) Guanylyl cyclases and signaling by cyclic GMP. Pharmacol Rev 52:375-414. Medline

Maklad A, Fritzsch B (2002) The developmental segregation of posterior crista and saccular vestibular fibers in mice: a carbocyanine tracer study using confocal microscopy. Brain Res Dev Brain Res 135:1-17. CrossRef Medline

Maklad A, Fritzsch B (2003) Development of vestibular afferent projections into the hindbrain and their central targets. Brain Res Bull 60:497-510. CrossRef Medline

Maklad A, Kamel S, Wong E, Fritzsch B (2010) Development and organization of polarity-specific segregation of primary vestibular afferent fibers in mice. Cell Tissue Res 340:303-321. CrossRef Medline

McCue MP, Guinan JJ Jr (1994) Acoustically responsive fibers in the vestibular nerve of the cat. J Neurosci 14:6058-6070. Medline

Nakamura H, O'Leary DD (1989) Inaccuracies in initial growth and arborization of chick retinotectal axons followed by course corrections and axon remodeling to develop topographic order. J Neurosci 9:3776-3795. Medline

Ozaki S, Snider WD (1997) Initial trajectories of sensory axons toward laminar targets in the developing mouse spinal cord. J Comp Neurol 380:215229. CrossRef Medline

Potter LR (2011) Guanylyl cyclase structure, function and regulation. Cell Signal 23:1921-1926. CrossRef Medline

Potter LR, Yoder AR, Flora DR, Antos LK, Dickey DM (2009) Natriuretic peptides: their structures, receptors, physiologic functions and therapeutic applications. Handb Exp Pharmacol 191:341-366. CrossRef Medline

Ratcliffe EM, Farrar NR, Fox EA (2011) Development of the vagal innervation of the gut: steering the wandering nerve. Neurogastroenterol Motil 23:898-911. CrossRef Medline

Rathjen FG, Schachner M (1984) Immunocytological and biochemical characterization of a new neuronal cell surface component (L1 antigen) which is involved in cell adhesion. EMBO J 3:1-10. Medline

Rinaman L, Levitt P (1993) Establishment of vagal sensorimotor circuits during fetal development in rats. J Neurobiol 24:641-659. CrossRef Medline

Rotolo T, Smallwood PM, Williams J, Nathans J (2008) Geneticallydirected, cell type-specific sparse labeling for the analysis of neuronal morphology. PLoS One 3:e4099. CrossRef Medline

Rubel EW, Fritzsch B (2002) Auditory system development: primary auditory neurons and their targets. Annu Rev Neurosci 25:51-101. CrossRef Medline

Ryugo DK, Parks TN (2003) Primary innervation of the avian and mammalian cochlear nucleus. Brain Res Bull 60:435-456. CrossRef Medline

Sato F, Sasaki H, Ishizuka N, Sasaki S, Mannen H (1989) Morphology of single primary vestibular afferents originating from the horizontal semicircular canal in the cat. J Comp Neurol 290:423-439. CrossRef Medline

Schmidt H, Rathjen FG (2010) Signalling mechanisms regulating axonal branching in vivo. Bioessays 32:977-985. CrossRef Medline

Schmidt H, Rathjen FG (2011) DiI-labeling of DRG neurons to study axonal branching in a whole mount preparation of mouse embryonic spinal cord. J Vis Exp pii:3667 CrossRef Medline

Schmidt H, Werner M, Heppenstall PA, Henning M, Moré MI, Kühbandner S, Lewin GR, Hofmann F, Feil R, Rathjen FG (2002) cGMP-mediated signaling via cGKIalpha is required for the guidance and connectivity of sensory axons. J Cell Biol 159:489-498. CrossRef Medline

Schmidt H, Stonkute A, Jüttner R, Schäffer S, Buttgereit J, Feil R, Hofmann F, Rathjen FG (2007) The receptor guanylyl cyclase Npr2 is essential for sensory axon bifurcation within the spinal cord. J Cell Biol 179:331-340. CrossRef Medline

Schmidt H, Stonkute A, Jüttner R, Koesling D, Friebe A, Rathjen FG (2009) C-type natriuretic peptide (CNP) is a bifurcation factor for sensory neurons. Proc Natl Acad Sci U S A 106:16847-16852. CrossRef Medline

Schmidt H, Ter-Avetisyan G, Rathjen FG (2013) A genetic strategy for the analysis of individual axon morphologies in cGMP signalling mutant mice. Methods Mol Biol 1020:193-204. CrossRef Medline

Stefanini M, De Martino C, Zamboni L (1967) Fixation of ejaculated spermatozoa for electron microscopy. Nature 216:173-174. CrossRef Medline

Tamura N, Doolittle LK, Hammer RE, Shelton JM, Richardson JA, Garbers 
DL (2004) Critical roles of the guanylyl cyclase B receptor in endochondral ossification and development of female reproductive organs. Proc Natl Acad Sci U S A 101:17300-17305. CrossRef Medline

Ter-Avetisyan G, Tröster P, Schmidt H, Rathjen FG (2012) cGMP signaling and branching of sensory axons in the spinal cord. Fut Neurol 7:639-651. CrossRef

Tsuji T, Kunieda T (2005) A loss-of-function mutation in natriuretic peptide receptor 2 (Npr2) gene is responsible for disproportionate dwarfism in cn/cn mouse. J Biol Chem 280:14288-14292. CrossRef Medline

Tsuru K, Otani K, Kajiyama K, Suemune S, Shigenaga Y (1989) Central terminations of periodontal mechanoreceptive and tooth pulp afferents in the trigeminal principal and oral nuclei of the cat. Brain Res 485:29-61. CrossRef Medline
Wegener JW, Nawrath H, Wolfsgruber W, Kühbandner S, Werner C, Hofmann F, Feil R (2002) cGMP-dependent protein kinase I mediates the negative inotropic effect of cGMP in the murine myocardium. Circ Res 90:18-20. CrossRef Medline

Windle WF (1926) Non-bifurcating nerve fibers of the trigeminal nerve. J Comp Neurol 40:229-240. CrossRef

Zhao Z, Ma L (2009) Regulation of axonal development by natriuretic peptide hormones. Proc Natl Acad Sci U S A 106:18016-18021. CrossRef Medline

Zhao Z, Wang Z, Gu Y, Feil R, Hofmann F, Ma L (2009) Regulate axon branching by the cyclic GMP pathway via inhibition of glycogen synthase kinase 3 in dorsal root ganglion sensory neurons. J Neurosci 29:1350 1360. CrossRef Medline 